\title{
Acute duodenal obstruction secondary to intussusception caused by the duodenal diverticulum: a case report
}

\author{
Yuchen Guo, Bin Liu, Ziwen Pan and Yang Zhang ${ }^{*}$ (D)
}

\begin{abstract}
Background: The duodenal intussusception is rarely reported and usually occurs secondary to organic diseases of the duodenum such as polyps, tumors and duplication cysts. Herein we report a case of duodenal intussusception caused by duodenal diverticulum.

Case presentation: A 21-year old male patient presented with abdominal pain and vomiting for one day. A contrast enhanced computed tomography of the abdomen revealed duodenal intussusception. On emergency laparotomy, the intussusception had reduced spontaneously while an invaginated diverticulum was seen at the junction of the descending and horizontal segments of the duodenum. The diverticulum was resected and the patient had uneventful recovery.
\end{abstract}

Conclusion: Duodenal intussusception is a rare complication of duodenal diverticulum. Being aware of this complication of diverticulum can help in timely diagnosis and treatment.

Keywords: Duodenal diverticulum, Intussusception, Endoscopy, Duodenal obstruction, Case report

\section{Background}

Intussusception is characterized by telescoping of the proximal bowel loop into the distal bowel. Primary idiopathic small bowel intussusception is common in children while secondary intussusception is usually present in adults with intestinal diseases such as tumor, polyps, tubercles, adhesions and Meckel diverticulum. However, the intussusception of duodenum is rarely reported. Herein, we report a case of duodenal diverticulum that invaginated in the duodenal lumen causing intussusception and obstruction. Very few such cases have been reported in the English literature [1].

\footnotetext{
* Correspondence: yangzhang@jlu.edu.cn

Department of Gastrointestinal Surgery, First Hospital of Jilin University, Changchun 130021, Jilin, China
}

(c) The Author(s). 2020 Open Access This article is licensed under a Creative Commons Attribution 4.0 International License, which permits use, sharing, adaptation, distribution and reproduction in any medium or format, as long as you give appropriate credit to the original author(s) and the source, provide a link to the Creative Commons licence, and indicate if changes were made. The images or other third party material in this article are included in the article's Creative Commons licence, unless indicated otherwise in a credit line to the material. If material is not included in the article's Creative Commons licence and your intended use is not permitted by statutory regulation or exceeds the permitted use, you will need to obtain permission directly from the copyright holder. To view a copy of this licence, visit http://creativecommons.org/licenses/by/4.0/ The Creative Commons Public Domain Dedication waiver (http://creativecommons.org/publicdomain/zero/1.0/) applies to the data made available in this article, unless otherwise stated in a credit line to the data.
A 21-year old male presented with severe intermittent abdominal pain, accompanied by vomiting for one day. Physical examination was unremarkable. During the admission, he underwent contrast enhanced computed tomography $(\mathrm{CT})$ of the abdomen which revealed a duodeno-jejunal intussusception (Fig. 1a-c). Presence of intestinal tumor or polyp could not be excluded. We could not perform a gastroscopy because of the severe symptoms of upper gastrointestinal obstruction of this patient. So, decision to perform exploratory laparotomy was taken. During the operation, the horizontal and descending segments of the duodenum were found to be dilated. However, no obvious intussusception or intestinal lesion was observed during the operation. So, we performed intraoperative gastroscopy via oral route. A large diverticulum was seen at the junction of the descending and horizontal segments of the duodenum, which had invaginated into the lumen of the duodenum 


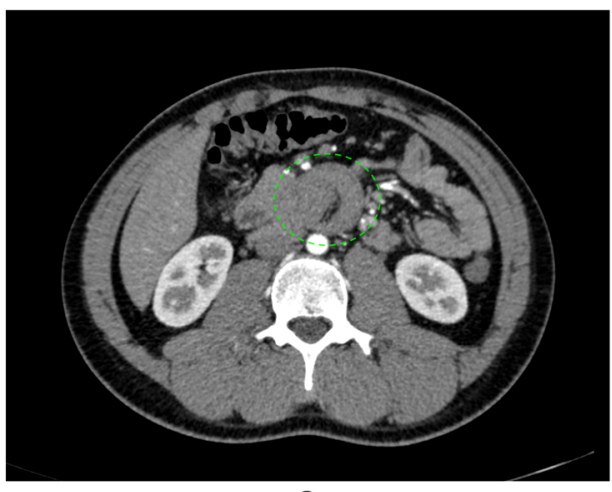

a

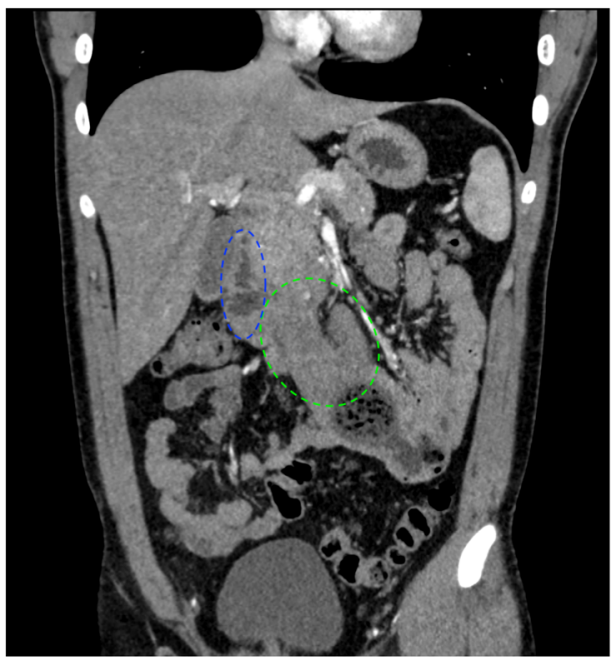

b

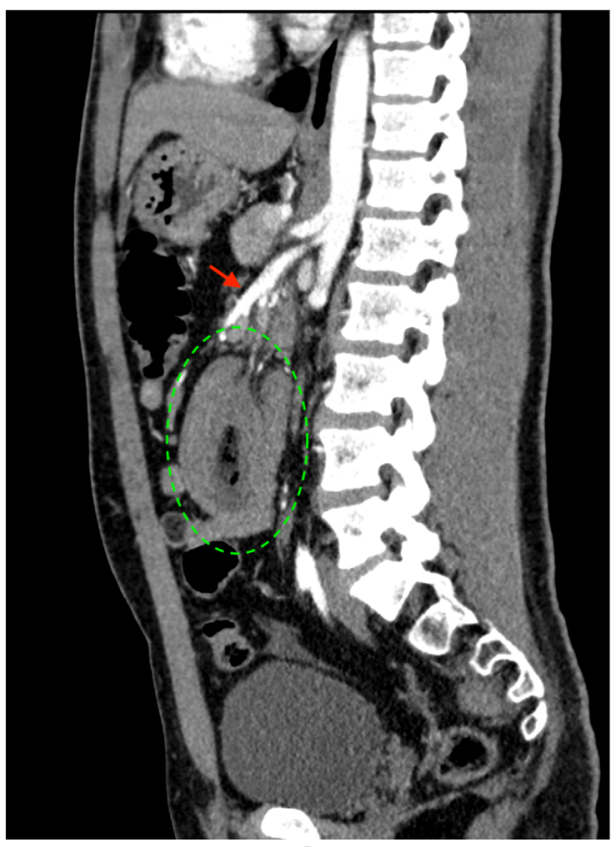

C
Fig. 1 a. The cross section of abdominal CT shows the typical bowel-within-bowel sign suggestive of duodenal intussusception into the jejunum (green circle). The intestinal wall of the head was thickened. The degree of strengthening was slightly reduced. Lumpy contents can be seen in the duodenal cavity. b. The coronal section of the CT scan shows the intussusception of duodenum into the jejunum (green circle) and the descending part of duodenum (blue circle) c. The sagittal section of the CT scan shows the intussusception (green circle) and its positional relation with superior mesenteric artery (red arrow)

(Fig. 2). Considering it to the lead point of intussusception, we planned the surgical excision of the diverticulum. We made incision at the base of the diverticulum, resected the duodenal diverticulum and sutured the duodenal incision (Fig. 3). The histopathological report of the resected specimen indicated presence of submucosal edema, vasodilatation, congestion and hemorrhage. Acute and chronic inflammatory cell infiltration was also present (Fig. 4). The postoperative recovery was uneventful with the postoperative hospital stay of 8 days. At one-year follow-up, the patient is symptom-free.

\section{Discussion and conclusions}

Bowel intussusception is rare in adults, accounting for $5 \%$ of the intussusceptions in all age group and 1-5\% cases of bowel obstruction in adults [2]. Among them, duodenal intussusception is extremely rare. Duodenal intussusception can occur because of the excessive mobility of the duodenal wall in cases with intestinal malrotation [3]. Duodenal intussusception without

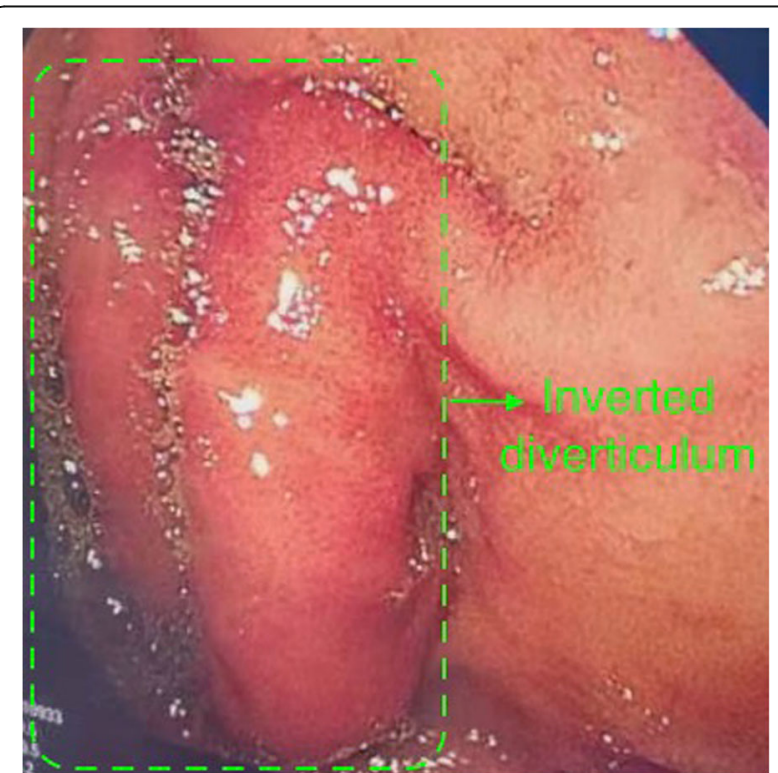

Fig. 2 A diverticulum was seen at the junction of the descending and horizontal segments of the duodenum, which had turned inward into the lumen of the duodenum (green arrow) 


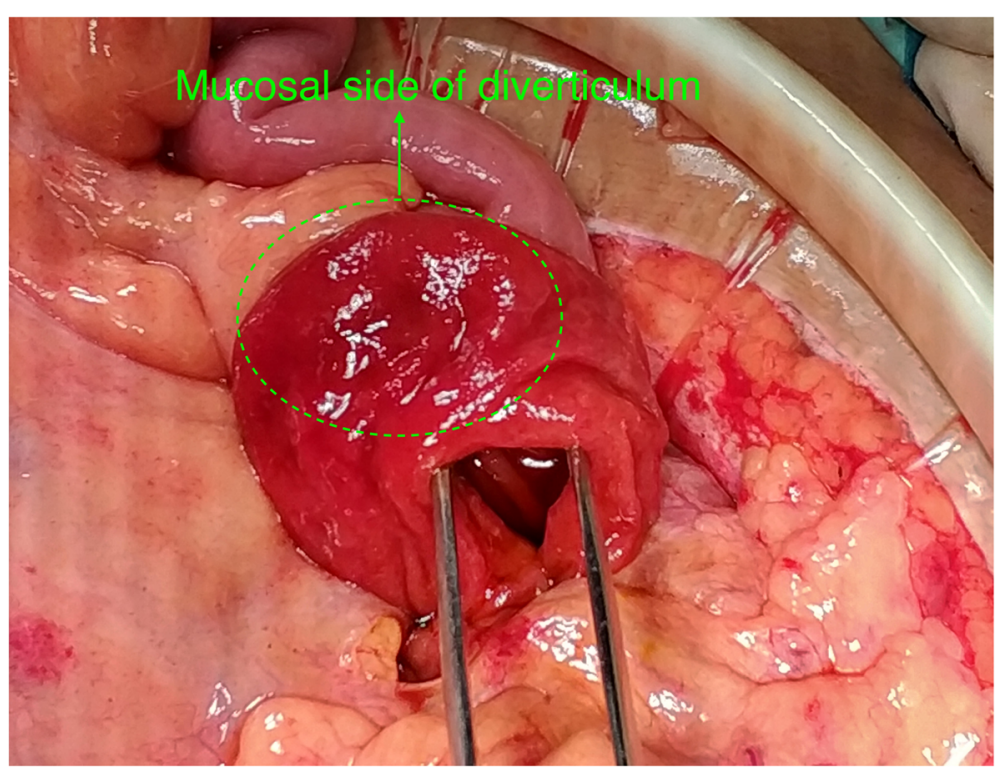

Fig. 3 Duodenal lumen was opened at the base of the diverticulum. The diverticulum was turned inside out. The green arrow indicates the mucosal side of the diverticulum

intestinal malrotation is usually not seen due to the relatively fixed retroperitoneal position of the duodenum. There are very few reports of the duodenal intussusception caused by various factors such as prolapse of duodenal tumors, ampullary lesions, duplication cysts, and congenital malrotation [3-6]. However, in the present case, duodenal intussusception occurred due to diverticulum. In extreme cases, duodenal intussusception can lead to biliary obstruction $[7,8]$.
Duodenum is the second most frequent site in the digestive tract for diverticular disease. Duodenal diverticulum mostly occurs in the second or third portion of the duodenum along the pancreatic or mesenteric border, and commonly near the ampulla of Vater [9]. Duodenal diverticula can be congenital or, more frequently, an acquired pseudodiverticula. They are usually asymptomatic. Approximately $5 \%$ of them are associated with complications, such as hemorrhage, obstruction, compression of biliopancreatic structures, inflammation and

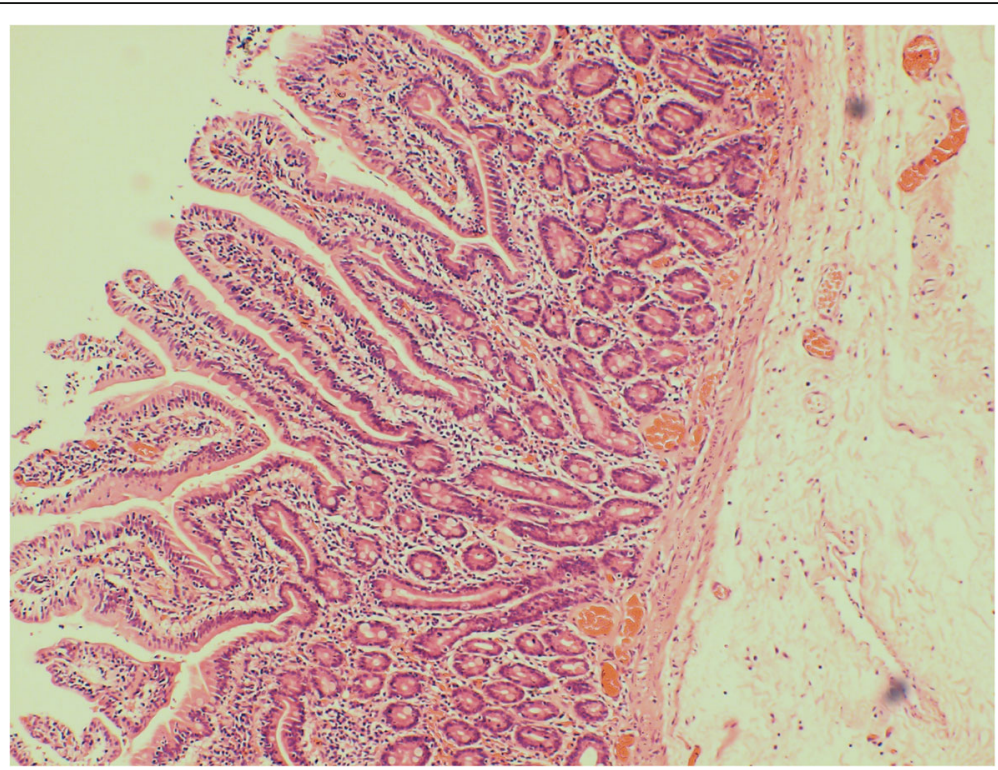

Fig. 4 The histopathological examination of the resected diverticulum revealed submucosal edema, vasodilatation, congestion and hemorrhage. Additionally, acute and chronic inflammatory cell infiltration was also seen 
perforation. In the current case, the duodenal diverticulum got invaginated into the lumen of the duodenum and got pushed into the proximal jejunum due to intestinal peristalsis leading to intussusception. However, we didn't observe the intussusception during the surgery due to spontaneous reduction, as reported in previous cases [10, 11]. Duodenal intussusception is generally transient and nonobstructive [11]. Sometimes the duodenal intussusception may retrograde spontaneously because of the poor mobility of the duodenal wall [10].

The clinical manifestations in adults with duodenal intussusception are usually non-specific and include nausea, vomiting and epigastric pain [6]. Abdominal $\mathrm{CT}$ is a very sensitive modality for diagnosis and can usually detect the lead point responsible for intussusception if present. CT may reveal the typical bowelwithin-bowel sign. However, mucosal prolapse can mimic these signs in the absence of intussusception [12]. Some cases of duodenal intussusception have been reported, but it is unclear whether this phenomenon is true intussusception or simple mucosal prolapse, which is misinterpreted as intussusception $[3,13,14]$. However, in the present case, the diverticulum had invaginated into the lumen of the duodenum, which acted as the lead point of the intussusception. So, we believe that the present case didn't had simple mucosal prolapse but intussusception. Endoscopy is another useful imaging modality for the diagnosis of intussusception and its lead point if present. Additionally, it is useful in making tissue diagnosis which helps in planning definitive treatment. Also, endoscopy may help reduce the duodenal intussusception before surgery. We believe that retrograde traction may occur due to gastric and proximal duodenal dilatation due to insufflation. However, this hypothesis needs to be proven by future studies. The management of duodenal intussusception depends on the underlying cause and severity of symptoms. If the cause is malignancy then pancreatoduodenectomy is required. It is a benign disease such as adenoma or polyp or diverticulum as seen in the present case then simple endoscopic or surgical excision of the lesion is curative. Some cases of intestinal malrotation precipitating duodenal intussusception may also require surgical correction.

Duodenal intussusception secondary to duodenal diverticulum is rarely reported. Duodenal intussusception should be considered in patients with duodenal diverticulum having persistent or recurrent abdominal symptoms. Detailed investigations should be performed to make the correct diagnosis. Endoscopy may help reduce the duodenal intussusception before surgery due to gastric and proximal duodenal dilatation due to insufflation.
However, this hypothesis needs to be proven by future studies.

\section{Abbreviation}

CT: Computed tomography

\section{Acknowledgements}

No acknowledgements.

Authors' contributions

YCG designed and drafted the work, and substantively revised it. BL has made contributions to acquisition of data and drafted the work. ZWP has made contributions to acquisition of data and drafted the work. YZ has made contributions to conception and design of the work, and substantively revised it. All authors have approved the submitted version (and any substantially modified version that involves the author's contribution to the study). All authors have agreed both to be personally accountable for the author's own contributions and to ensure that questions related to the accuracy or integrity of any part of the work, even ones in which the author was not personally involved, are appropriately investigated, resolved, and the resolution documented in the literature.

\section{Funding}

No funding was received.

\section{Availability of data and materials}

Not applicable.

Ethics approval and consent to participate

Ethical approval was obtained from the Ethics Committee of First Hospital of Jilin University.

\section{Consent for publication}

The written consent to publish the personal and clinical details (including figures) of the participant was obtained from study participant.

\section{Competing interests}

There are no competing interests.

Received: 14 March 2020 Accepted: 12 July 2020

Published online: 22 July 2020

\section{References}

1. Griffin M, Carey WD, Hermann R, Buonocore E. Recurrent acute pancreatitis and intussusception complicating an intraluminal duodenal diverticulum. Gastroenterology. 1981;81(2):345-8.

2. Azar T, Berger DL. Adult intussusception. Ann Surg. 1997:226(2):134-8.

3. Gardner-Thorpe J, Hardwick RH, Carroll NR, Gibbs P, Jamieson NV, Praseedom RK. Adult duodenal intussusception associated with congenital malrotation. World J Gastroenterol. 2007;13(28):3892-4.

4. Eduardo TD, Raúl PD, Juan CDP, José GSF. Imaging findings of duodenal duplication cyst complicated with duodenal intussusception and biliary dilatation. Case Rep Radiol. 2016;2016:1-3.

5. Pradhan D, Kaur N, Nagi B. Duodenoduodenal intussusception: Report of three challenging cases with literature review. J Cancer Res Ther. 2015;11(4): 1031

6. Lingala S, Moore A. Unusual presentation of duodenal ulcer presenting with duodenal intussusception. Acg Case Reports J. 2018;5:e25.

7. Pérez-Torres E, Fosado-Gayosso M, Gil-Rojas N, Tijera MdFHI. Duodenobiliary obstruction in Peutz-Jeghers syndrome. Cir Cir. 2011;79(2):186-90.

8. De Silva WSL, Pathirana AA, Gamage BD, Manawasighe DS, Jayasundara B, Kiriwandeniya U. Extra-ampullary Peutz-Jeghers polyp causing duodenal intussusception leading to biliary obstruction: a case report. J Med Case Rep. 2016;10(1):196.

9. Chad TM. The Perforated Duodenal Diverticulum. Arch Surg. 2012;147(1):81.

10. Hirata M, Shirakata Y, Yamanaka K. Duodenal intussusception secondary to ampullary adenoma: a case report. World J Clin Cases. 2019;7(14):1857-64.

11. Sandrasegaran K, Kopecky KK, Rajesh A, Lappas J. Proximal small bowel intussusceptions in adults: CT appearance and clinical significance. Abdom Imaging. 2004;29(6):653-7. 
12. Choi SH, et al. Intussusception in adults: from stomach to rectum. AJR Am J Roentgenol. 2004;183(3):691-8.

13. Ijichi H, Kawabe T, Isayama H, Yamagata M, Makuuchi M. 'Duodenal intussusception' due to adenoma of the papilla of Vater. HepatoGastroenterology. 2003;50(53):1399-402.

14. Saida Y, Matsueda K, Itai Y. Distal migration of duodenal tumors: simple prolapse or intussusception? Abdom Imaging. 2002;27(1):9-14.

\section{Publisher's Note}

Springer Nature remains neutral with regard to jurisdictional claims in published maps and institutional affiliations.

Ready to submit your research? Choose BMC and benefit from:

- fast, convenient online submission

- thorough peer review by experienced researchers in your field

- rapid publication on acceptance

- support for research data, including large and complex data types

- gold Open Access which fosters wider collaboration and increased citations

- maximum visibility for your research: over $100 \mathrm{M}$ website views per year

At $\mathrm{BMC}$, research is always in progress.

Learn more biomedcentral.com/submissions 